retinal receiving area. It is, however, a noteworthy circumstance that these natives are able to pass from the bright tropical glare outside their dwellings to the dark interiors, and vice vers $\hat{a}$, without showing the temporary derangement of vision which the white man experiences whilst the iris is adapting itself 1.) the new condition.

17. Wood Lane, Falmouth, March 30

H. B. Guppy

\section{Mr. Lowne on the Morphology of Insects' Eyes}

IN reference to the discussion between Dr. Sydncy Hickson and Mr. Benjamin Lowne, I beg to state that I have been favoured by both of those gentlemen with opportunities of carefully studying their preparations, and I fcel it to be my duty to state that in my judgment Mr. Lownc's preparations do not justify the conclusions which he has based on them, and are, in fact, not made with that skill and knowledge of modern histological method which is necessary in order that trustworthy conclusions may be obtained. On the other hand, Dr. Hickson's preparations are thoroughly satisfactory as examples of histological manipulation. Dr. Hickson supports the accepted view as to the termination of the optic nerve-fibres in the nerve-end cells of the retinulæ. Mr. Lowne denies this conncction. I have no doubt that such a connection cannot be readily observed in $\mathrm{Mr}$. Lowne's preparations, At the same time I have no doubt whatever that this is because the preparations are badly made. Mr. Lowne's preparations fail to show many other simple features in the structure of the insect's eye, which are readily seen in preparations made by the application of methods now recognised and approved, but not made use of by Mr. Lowne.

I am sorry to see the resources of the Linnean Society employed in publishing a memoir the conclusions of which, although startling in their novelty, are undeniably based upon the mistaken interpretation of defective preparations.

I think it is important that the Fellows of the Linnean Society should know whether the memoir now published is the same which was read a year or two ago at the Royal Society, and whether the Council of the Royal Socicty took any steps to ascertain the value of Mr. Lowne's preparations, or came to any decision as to the fitness of Mr. Lowne's paper for publication. March 14 E. RAY LANKESTER

\section{On the Terminology of the Mathematical Theory of Elasticity}

ENGINEERS quite as much as "elasticians" have reason to want some such terminology as that sought by Prof. Pearson (NATURE, vol. xxxi. p. 456), and have equal reason to be indebted to him for undertaking the work which he has at present in hand, which seems already to have given results of practical value as great as their scientific interest.

As I have for some years made a study of the physical side of the problems mentioned by him, I should be glad to make some suggestions as to terminology as contributions to the discussion of the subject in your columns. I will confine what I have to say to what may be called ductile materials (such as wrought iron, ordinary steel, copper, \&c), because in these only the whole phenomena are visible. The behaviour of such matcrial in teusion is illustrated by the accompanying figure, in which stresses are measured along the horizontal, and strains along the vertical axis.

It is extremcly rare to obtain a piece of raw material already in a state of ease. Wire, of course, is highly strained by its process of manufacture, but that even ordinary bar and plate is also slightly strained, is shown in the manner mentioned by Prof. Pearson. Such initial strains as become visible as set by the first stretching up to any load (within limit of elasticity) disappear after one or two applications of that load. The material is then in a state of ease up to that load, but higher loads (still within the limit), on their first application, generally produce more set the state of ease thus extending only to the stress employed to produce it. The sets are, along with the elastic strain, proportional to the stress, their cffect being simply to lower the moriulus of elasticity. Probably the process of annealing will bring the material into a state of ease for all loads at which such a state is possible. I propose to examine this matter further by aid, if possible, of the apparatus described by Prof. D. E. Hughes in the Inst. M. Eng. Proc., $188_{3}$, p. 73 . In the figure, a represents this condition of perfect eltasticity (maximum state o case heing presupposed) and $\mathrm{B}$, the superior limit of this con dition, is the mathematical limit of perfect elasticity.

After $\mathrm{B}$ comes a stage $b$, within which the set is not proportional to the stress, although it still remains small ; the total ex tension, therefore, increases faster than the stress. Occasionally this stage does not occur at all, and both. its higher and lower limits seem-more than any other points in the life of the material- to be susceptible of change depending on manipula. tion. Accidental shock will shorten the stage considerably ; very gradual loading extends it somewhat. For these and other reasons I therefore suggest that this stage be cal'ed the condition of inslability, or of unstable iquiibrium.

This condition terminates at $\mathrm{c}$, in what I have called a "breaking-down" in the paper referred to by Prof. Pcarson, in which paper I believe the phen menon was described for the first time. This point is the one called by engineers the limit of elasticity, because it is the only one markedly visible without special apparatus. (The extension at $\mathrm{B}$, on a length of $\mathrm{IO}$ iuches, may be about $\mathrm{O}^{\circ} \mathrm{O}$ inch; at $\mathrm{CO}^{\circ} \mathrm{O} 3$ inch and at $\mathrm{C}_{1}$, same stress, it increases to $0^{\circ} 20,0^{\circ} 25$, and even occasionally $0^{\prime} 4$ inch.) If "breahing-down point" be too crude a name, I would sug gest limit of labi ity. It should be noted that the stress at this

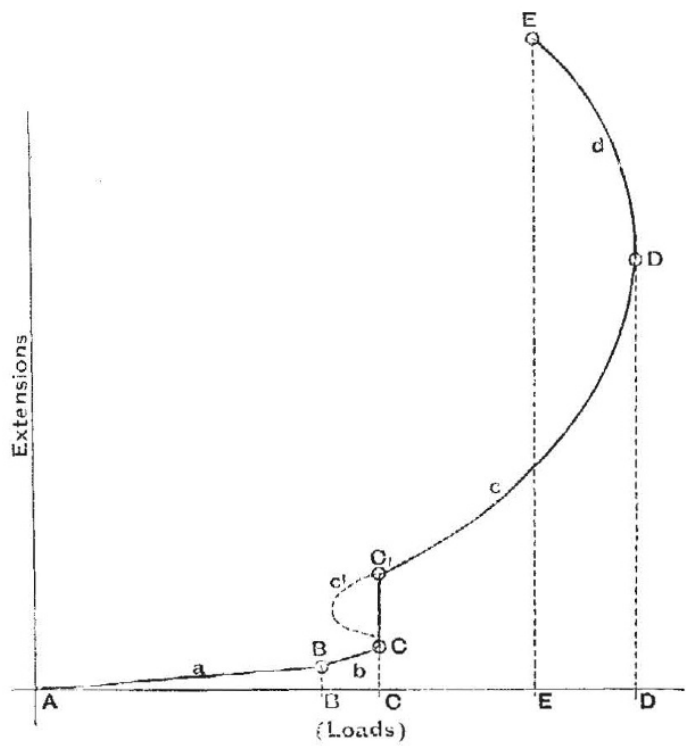

point does not remain constant, but in reality appears to diminish as the extension goes on, as shown at $c^{\prime}$ (ihis dotted curve not drawn to scale), a matter on which $I$ am at prescnt experimenting. I should ndd that, during the application of load at this point, extension appears to be occurring at different parts of the length successivtly, and not at all parts simultaneously, as during conditions $a$ and $c$.

In the next $s$ tage, $c$ to $D$, the whole strains consist of a very small ela tic portion (apparently closely following the modulus), and a very large set, increasing much faster than the stress. The test bar remains at each load practically constant in its cross-section at all points of its length, and rises in temperature instead of (as in condition a) cooling. I would suggest for this stage the name condition of uniform flow, the physical applica. bility of which will be obvious to any one who has seen ductile mctal in this condition.

At some point, $D$, a maximum load is reached, and at about the same point (generally, I think, a little earlier, but the differ. ence is small, and not very easy to get at with certainty) the metal begins to flow locally, a part becoming much more reduced in cross-section than the rest, and eventually fracture occurs at this place under a less load than D, but with a greater extension, as at E. This final stage, $d$, might be called condition of local flow. The loads D and E (as Prof. Pearson suggests) would be max imum and terminal loads respectively). (Their difference was first pointed out, I think, by Mr. Daniel Adamson's experiments, Journal I. and S. Inst., I878). The maximum intensity of stress 